\title{
In Vivo Recording of Nerve Conduction Velocity of Spinal CNS Fibers in the Mouse
}

\author{
P. DIBAJ ${ }^{1}$, E. D. SCHOMBURG ${ }^{1,2}$ \\ ${ }^{1}$ Max-Planck-Institute for Experimental Medicine, Göttingen, Germany, ${ }^{2}$ Institute of Physiology, \\ University of Göttingen, Germany
}

Received September 13, 2016

Accepted December 5, 2016

\begin{abstract}
Summary
Anesthetic and surgical procedures and an electrophysiological method were developed for recording nerve conduction velocity (NCV) of CNS fibers in the murine spinal cord. Under intravenous anesthesia and artificial ventilation the lumbar spinal cord segments $L 1$ to $L 4$ and dorsal roots $L 3$ to $L 5$ on the left side were exposed by laminectomy. After stimulation of the dorsal root L4, a compound action potential (CAP) was recorded at the ipsilateral left fasciculus gracilis at the spinal cord level L1. The latency from stimulation to the CAP together with the measured distance between the electrodes was used for the determination of the NCV. NCV of the fastest fibers in the fasciculus gracilis was observed to be approximately $28 \mathrm{~m} / \mathrm{s}$. Reversible decrease of the NCV was measured, in vivo, under general hypothermia. The technique described serves for in vivo electrophysiological investigations of spinal central fibers in wildtype and mutant mice.
\end{abstract}

\section{Key words}

In vivo electrophysiology in mice - Spinal cord • CNS fibers • Nerve conduction velocity

\section{Corresponding author}

P. Dibaj, Max-Planck-Institute for Experimental Medicine, D-37075 Göttingen, Germany. E-mail: Dibaj@em.mpg.de

In vivo electrophysiological investigations in mice for the purpose of recording nerve conduction velocity $(\mathrm{NCV})$ have been performed predominantly in the peripheral nervous system. Measurements of the NCVs of afferent and efferent fibers in different peripheral nerves of the mouse have been carried out (Steffens et al. 2012). Further, in vivo measurements have been described on different peripheral nerves in mice (Moldovan and Krarup 2006, Schulz et al. 2014, Hoffmann et al. 2015). Within the CNS, in vivo motor and somatosensory evoked potential (MEP and SSEP) recordings have been used to determine differences in $\mathrm{NCV}$ of central fibers between wildtype mice and knock-out mice for an oligodendrocyte protein (Lee et al. 2011). However, the accuracy of NCV of central fibers measured by MEP and SSEP is compromised due to the contribution of the synaptic delay to the measured latencies. NCV measurements within the CNS have been mainly realized ex vivo using dissected optic nerves in incubation chambers (Etxeberria et al. 2016).

In this report, we describe a technique for in vivo electrophysiology of sensory fibers of the dorsal spinal cord in the mouse. The experiments were performed according to the ethical guidelines of the national animal protection law and were authorized by the ethical committee of the state of lower Saxony. Adult wildtype C57BL/6 mice of 3 to 12 month of age were used.

For initial anesthesia, $80 \mathrm{mg} / \mathrm{kg}$ pentobarbital was injected intraperitoneally. After placing the mouse on a heated support and cannulation of the jugular vein with a $0.61 \mathrm{~mm}$ catheter, anesthesia was continued intravenously with 40 to $60 \mathrm{mg}$ methohexital-sodium per $\mathrm{kg}$ and hour. Tracheotomy was performed and a tube inserted for artificial ventilation with a gas mixture of $\mathrm{CO}_{2} \quad(2.5 \%), \quad \mathrm{O}_{2} \quad(47.5 \%)$ and $\mathrm{N}_{2} \quad(50 \%)$ at 120 strokes/min $(120-160 \mu 1 /$ stroke depending of the 
weight of the mouse). To avoid recording artefacts by active respiratory and reflexogenic movements the mice were paralyzed $(800 \mu \mathrm{g} / \mathrm{kg}$ pancuronium, supplemented i.p. every hour). Rectal body temperature (kept at $37-38{ }^{\circ} \mathrm{C}$ by manually regulating the power of the heated support), heart rate (ECG was recorded via platinum wires into both forelegs) and $\mathrm{O}_{2}$ blood saturation (sensor in the inguinal region; MouseOx ${ }^{\circledR}$, Starr Life Sciences, Oakmont, USA) were continuously monitored (Fig. 1A). Appropriate dose of anesthesia was initially proofed by the absence of corneal and pinna reflexes. Later after injection of pancuronium, it was controlled by falling body temperature and heart rate.
After incision of the skin and removal of tendons and muscle tissue from the lumbar dorsal spinal processes and spinal arcs, a laminectomy was performed from vertebrae L1 to L5 to expose the spinal cord segments L1 to L4 and the left dorsal roots L3 to L5 (Fig. 1A). After paralyzation, the dura mater was removed to mobilize the dorsal roots. To avoid motion artefacts the vertebral column was rigidly fixed with two custom-made clamps (Fig. 1A; for more details regarding anesthetic and surgical procedures refer our previous reports: Dibaj et al. 2010, Dibaj et al. 2011, Dibaj et al. 2012, Steffens et al. 2012, Schomburg et al. 2013).
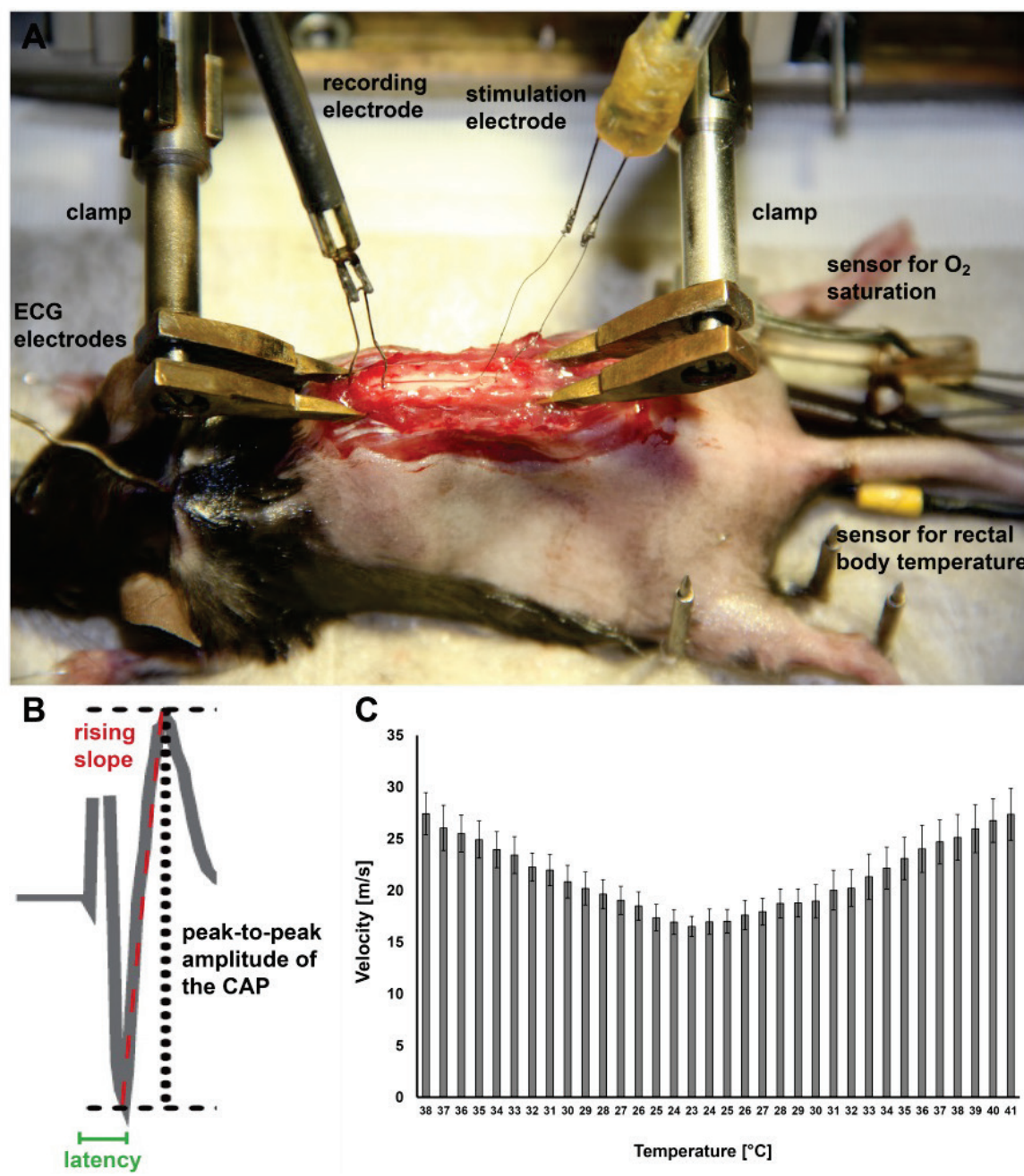

Fig. 1. In vivo recording of dorsal spinal fibers in the mouse. (A) Exposed lumbar spinal cord after laminectomy. Stimulation at the left dorsal root L4 and recording further cranial (left in the picture) at the ipsilateral left fasciculus gracilis at spinal cord level L1 were performed by respective bipolar platinum wire electrodes. Vertebral column was rigidly fixed with two custom-made clamps. ECG was recorded via platinum wires into both forelegs. $\mathrm{O}_{2}$ blood saturation was recorded via a sensor in the right inguinal region. Body temperature was monitored by a rectal sensor. (B) Compound action potential (CAP); red dotted line marks the rising slope (upstroke) of the CAP. The latency between the stimulation time and the beginning of the rising slope together with the distance between the electrodes was used for the measurement of the NCV. C shows a reversible reduction of the NCV under hypothermic condition. Body temperature was reversibly reduced from $38^{\circ} \mathrm{C}$ to $23^{\circ} \mathrm{C} . \mathrm{n}=5$ adult C57BL/6 mice; SEM.
For electrophysiology studies, the spinal cord was covered with mineral oil and the mice were grounded via the clamps fixating the vertebral column. Stimulation and recording were performed using thin bipolar platinum wire electrodes (Fig. 1A). Rectangular constant voltage pulses with duration of $0.1 \mathrm{~ms}$ were used to stimulate the left dorsal root L4. Different stimulation strengths were used: $1.5 \mathrm{~T}, 2 \mathrm{~T}, 5 \mathrm{~T}, 10 \mathrm{~T}, 20 \mathrm{~T}$ and $50 \mathrm{~T}$ (the strength being indicated by multiples of the threshold strength for the activation of the lowest threshold fibers $\mathrm{T}$; more details are in Saab et al. 2016). The relatively high stimulation strength of $5 \mathrm{~T}$ was used for the determination of the NCV (Patzig et al. 2016). CAP recording was performed with a sampling rate of $50 \mathrm{kHz}$ 
with a surface electrode at the ipsilateral left fasciculus gracilis at spinal cord level L1. The signal was amplified (around 10k) and appropriately filtered (low pass $0.1 \mathrm{~Hz}$; high pass $30 \mathrm{kHz}$ ). At the end of the experiment, the distance was measured in situ between the stimulation electrode (cathode) and the recording electrode. The latency from stimulation to the first peak of the CAP together with the distance between the electrodes was used for the determination of the NCV (Fig. 1B). NCV of the fastest fibers in the fasciculus gracilis was approximately $28 \mathrm{~m} / \mathrm{s}$. Since the temperature of the oil over the spinal cord was around $34-35{ }^{\circ} \mathrm{C}$ (core temperature $37-38^{\circ} \mathrm{C}$ ), the $\mathrm{NCV}$ is lightly (approximately $10 \%$ ) underestimated (Fig. 1C). The same NCV was determined by recording from fasciculus gracilis at two different distances from the root entry zone L4. Therefore, NCV of ascending fibers in dorsal root as well as in fasciculus gracilis can be assumed to be similar. Under hypothermic condition, induced by continuous reduction of the support power, a reversible decrease of the NCV was observed in vivo (Fig. 1C). We measured a NCV reduction of approximately $40 \%(28 \mathrm{~m} / \mathrm{s}$ to $16.5 \mathrm{~m} / \mathrm{s}$, decreasing temperature from $37-38^{\circ} \mathrm{C}$ to $\left.23{ }^{\circ} \mathrm{C}\right)$.

In summary, a method was developed for stable in vivo electrophysiology of sensory CNS fibers within the dorsal spinal column. The advantage of our presented method with i.v. anesthesia and artificial respiration is the possibility of the paralyzation of the mouse which distinctly reduces movement artefacts. The method enables the determination of conduction properties of nerve fibers in the CNS of wildtype mice and in mice with transgenic modifications of CNS properties.

\section{Conflict of Interest}

There is no conflict of interest.
Abbreviations
CAP - compound action potential
$\mathrm{CNS}$ - central nervous system
$\mathrm{NCV}$ - nerve conduction velocity.

\section{References}

DIBAJ P, NADRIGNY F, STEFFENS H, SCHELLER A, HIRRLINGER J, SCHOMBURG ED, NEUSCH C, KIRCHHOFF F: NO mediates microglial response to acute spinal cord injury under ATP control in vivo. Glia 58: 1133-1144, 2010.

DIBAJ P, STEFFENS H, ZSCHÜNTZSCH J, NADRIGNY F, SCHOMBURG ED, KIRCHHOFF F, NEUSCH C: In Vivo imaging reveals distinct inflammatory activity of CNS microglia versus PNS macrophages in a mouse model for ALS. PLoS One 6: e17910, 2011.

DIBAJ P, ZSCHÜNTZSCH J, STEFFENS H, SCHEFFEL J, GÖRICKE B, WEISHAUPT JH, LE MEUR K, KIRCHHOFF F, HANISCH UK, SCHOMBURG ED, NEUSCH C: Influence of methylene blue on microgliainduced inflammation and motor neuron degeneration in the SOD1 (G93A) model for ALS. PLoS One 8: e43963, 2012.

EXTEBERRIA A, HOKANSON KC, DAO DQ, MAYORAL SR, MEI F, REDMOND SA, ULLIAN EM, CHAN JR: Dynamic modulation of myelination in response to visual stimuli alters optic nerve conduction velocity. J Neurosci 36: 6937-6948, 2016.

HOFFMANN T, DE COL R, MESSLINGER K, REEH PW, WEIDNER C: Mice and rats differ with respect to activitydependent slowing of conduction velocity in the saphenous peripheral nerve. Neurosci Lett 592: 12-16, 2015.

LEE X, HU Y, ZHANG Y, YANG Z, SHAO Z, QIU M, PEPINSKY B, MILLER RH, MI S: Oligodendrocyte differentiation and myelination defects in OMgp null mice. Mol Cell Neurosci 46: 752-761, 2011.

MOLDOVAN M, KRARUP C: Evaluation of $\mathrm{Na}+/ \mathrm{K}+$ pump function following repetitive activity in mouse peripheral nerve. J Neurosci Methods 155: 161-171, 2006.

PATZIG J, ERWIG MS, TENZER S, KUSCH K, DIBAJ P, MÖBIUS W, GOEBBELS S, SCHAEREN-WIEMERS N, NAVE KA, WERNER HB: Septin/anillin filaments scaffold central nervous system myelin to accelerate nerve conduction. Elife 5: e17119, 2016.

SAAB AS, TZETANOVA ID, TREVISIOL A, BALTAN S, DIBAJ P, KUSCH K, MÖBIUS W, GOETZE B, JAHN HM, HUANG W, ET AL.: Oligodendroglial NMDA receptors regulate glucose import and axonal energy metabolism. Neuron 91: 119-132, 2016. 
SCHULZ A, WALTHER C, MORRISON H, BAUER R: In vivo electrophysiological measurements on mouse sciatic nerves. $J$ Vis Exp 86: e51181, 2014.

SCHOMBURG ED, KALEZIC I, DIBAJ P, STEFFENS, H: Reflex transmission to lumbar $\alpha$-motoneurones in the mouse similar and different to those in the cat. Neurosci Res 76: 133-140, 2013.

STEFFENS H, DIBAJ P, SCHOMBURG ED: In vivo electrophysiology in mice: conduction velocities in afferent and efferent nerve fibre groups. Physiol Res 61: 203-214, 2012. 